\title{
Mechanical and histomorphometrical evaluation of false and floating ribs of young adults with idiopathic scoliosis
}

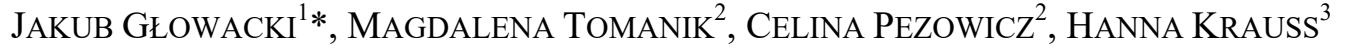 \\ ${ }^{1}$ Department of General Orthopaedics, Musculoskeletal Oncology and Trauma Surgery, \\ Poznan University of Medical Sciences, Poznań, Poland. \\ ${ }^{2}$ Department of Mechanics, Materials and Biomedical Engineering, \\ Wrocław University of Science and Technology, Wrocław, Poland. \\ ${ }^{3}$ Department of Medicine, The President Stanisław Wojciechowski State University of Applied Sciences, Kalisz, Poland.
}

\begin{abstract}
Purpose: The aim of this paper was to assess the histomorphometrical and mechanical properties of ribs in patients with idiopathic scoliosis who underwent corrective surgery of scoliosis combined with thoracoplasty. Methods: The analyzed material encompasses 20 females between the ages of 12 and 18, whose pre-operative Cobb angle was 56.85 degrees, on average. The participants were divided into two age groups, up to the age of 15 and above 15 years old, taking into account the anatomical location of the assessed rib fragments with a division into floating and false ribs. The analysis of mechanical parameters was carried out by means of the quasi-static 3-point bending test, and the histomorphometric evaluation of the examined rib fragments was carried out using high-resolution computed tomography. Results: The existence of explicit relationships between selected radiological parameters describing scoliosis and mechanical and histomorphometric parameters of the ribs has not been confirmed. Statistically significant correlations between age and rib stiffness as well as between Young's modulus and stiffness depending on the anatomical location of the examined rib fragment were confirmed. Conclusions: Mechanical and histomorphometric properties of bone tissue in patients with scoliosis are not explicitly associated with the radiological parameters characterizing scoliosis.
\end{abstract}

Key words: ribs, histomorphometrical parameters, mechanical parameters, scoliosis

\section{Introduction}

Since the middle of the last century, in the world literature, there have been a number of papers discussing the mechanical properties of ribs. Early research was mostly based on evaluation of bone fragments collected from deceased donors, often without taking into account the metabolic burden on the body in the form of diseases that led to death [1], [6], [12], [20], [21], [25]. Other authors perform biomechanical analysis with the use of finite element method [7]. Only a few studies included an analysis of the properties of bone tissue collected from young people who overall were also in good health [17].
Conducting this type of research using unique material collected in vivo is possible for people with scoliosis who underwent a surgery, combined with rib hump correction - thoracoplasty. To pre-empt questions about the representativeness of the analyzed sample, one must realize that the simple transfer of test results in patients onto a healthy population carries a risk resulting from certain differences in the group of patients with scoliosis. Those disorders include lower BMI values which are most frequently described in the literature, as well as osteopenia, which statistically more frequently affect the population of patients with scoliosis. The reason for these differences can be seen both in the reduced physical activity of the patient population, as well as

\footnotetext{
* Corresponding author: Jakub Głowacki, Department of General Orthopaedics, Musculoskeletal Oncology and Trauma Surgery, Poznan University of Medical Sciences, ul. 28 Czerwca 1956 135/147, 61-545 Poznań, Poland. Phone: +48 697696035, e-mail: kubaglowacki@o2.pl

Received: December 5th, 2019

Accepted for publication: February 25th, 2020
} 
the impact of the disease itself on the overall metabolic state of the body [2].

The aim of the study was to assess the mechanical and histomorphometric properties of ribs in people with idiopathic scoliosis taking into account the age of the patients, and to look for correlations between these parameters and selected measurements describing spinal deformation in the frontal and sagittal plane.

\section{Material and methods}

The research material consisted of rib fragments ( $n=43)$ taken subperiosteally, according to the method described by Suk et al. [22], which were not used to produce anterior interbody fusion. The biological material came from female patients $(n=20)$, 12 to 18 years old, who were diagnosed with type 5 scoliosis according to Lenke. They were all surgically treated with anterior access combined with anterior interbody fusion in the years 2014-2017. Exclusion criteria included the diagnosed scoliosis of known etiology, past chest or spine surgery. In addition, people with systemic conditions potentially affecting bone metabolism, including those using steroid drugs, were excluded from the study. From the time of the operation until the tests were performed, the biological material was stored in tightly closed polyethylene containers at $-20^{\circ} \mathrm{C}$ not to affect the changes in the mechanical properties of bone tissue [8].

The collected research material was divided into two groups, according to the anatomical structure of the chest separating the ribs, and in accordance to the type of connection with the sternum. Fragments originating from ribs VIII, IX, X and XI, XII were classified into the group of false $(n=27)$ and floating $(n=16)$ ribs, respectively. Moreover, to determine the impact of age on the mechanical parameters of the ribs, the biological material was divided into two age groups, i.e., younger $(n=31)$ - up to 15 years of age, and older $(n=12)$ - over 15 years of age.

\subsection{Clinical characteristics of scoliosis}

Among the parameters characterizing scoliosis, the following criteria were taken into account: pre-operative Cobb angle, apical vertebrae translation, kyphosis angle between 5 and 12 , value of pre-operative percent of correction in corrective tilt determined according to the methodology used by the Harms Study Group [4].

\subsection{Histomorphometry and degree of rib mineralization}

The analysis of the geometrical dimensions of the ribs and the assessment of the structural properties of bone tissue were carried out using a SkyScan1172 high resolution computer microtomograph from Bruker. In the reconstruction process, cross-sections with a resolution of $12.5 \mu \mathrm{m}$ were obtained based on the recorded projections.

The basic parameters determined in the quantitative analysis were the cortical thickness (Ct.Th) and its volume (Ct.Vol), as well as the cortical area (Ct.Ar) and trabecular area (Tr.Ar) (Fig. 1).

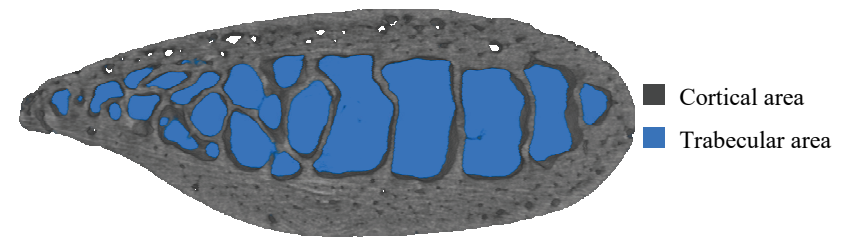

Fig. 1. The cross-section of the rib explaining the cortical and trabecular area definition

For the central part of the ribs, corresponding to the load application site in the 3-point bending test (Fig. 2), precisely determined was the moment of inertia $I_{x}$, necessary for the mechanical parameters to be defined (1).

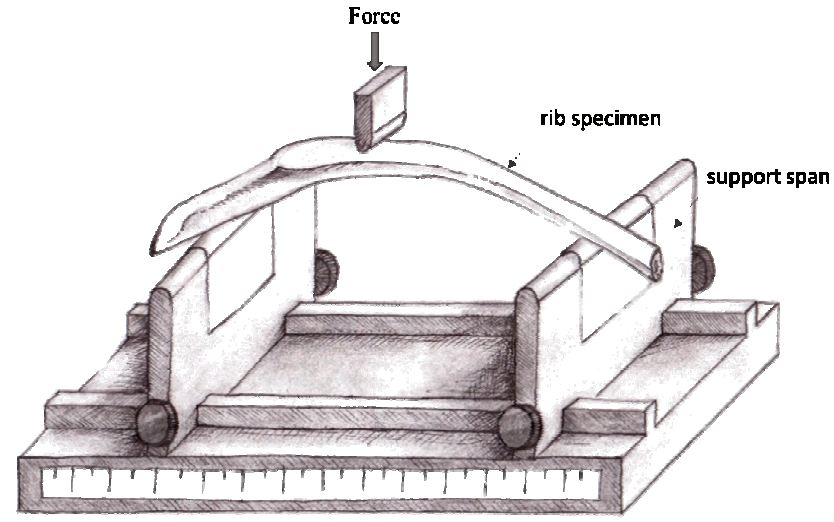

Fig. 2. Measuring setup for 3-point bending of the rib [19]

Based on the x-ray attenuation coefficient, calibrated against the known bone tissue phantom, the bone mineral density (BMD) of the ribs was calculated.

\subsection{Mechanical properties}

The assessment of the mechanical properties of the ribs was carried out using the 3-point bending method (Fig. 2) [5], [19]. 
The tests were carried out on the MTS MiniBioniks 858 testing machine with a constant load speed of $2 \mathrm{~mm} / \mathrm{min}$. The measurement was carried out until the bone broke. During the 3-point bending test, the fragments of ribs were placed on the supports of the measuring setup, acting with a concentrated force from the outside to the inside of the chest, the distance between the system's supports was $60 \mathrm{~mm}$. During the tests, the changes in the force $F[\mathrm{~N}]$ in the function of displacement $f[\mathrm{~mm}]$ of the sample were recorded.

Based on the collected data, parameters such as Young's modulus $E$, calculated on the basis of formula (1), and bending moment $M_{g}$, calculated in accordance with formula (2), were determined. Additionally, the bending stiffness $K$ was determined, which is the product of the Young's modulus and the moment of inertia $I_{x}$.

$$
\begin{aligned}
& E=\frac{F_{\max } \cdot l^{3}}{48 \cdot f \cdot I_{x}}[\mathrm{MPa}], \\
& M_{g}=\frac{F_{\max } \cdot l}{4}[\mathrm{~N} \cdot \mathrm{m}] .
\end{aligned}
$$

\subsection{Statistical analysis}

To determine the statistically significant differences between the analyzed groups and to determine the correlation between individual parameters, first the outliers (Grubbs's test) were rejected and distribution normality (Shapiro-Wilk test) was checked; depending on the type of distribution, the Pearson's linear correlation coefficient and Spearman's $R_{s}$ were determined for compatible and non-compliant distributions, respectively. Then, the assumption of equal variances for unrelated samples was checked and statistical significance was determined. For the other distributions, statistical significance was determined using the KruskalWallis $H$-test. To compare morphometric data and mechanical parameters between the analyzed groups, the Student's $t$-test was calculated for unrelated samples (distribution consistent with the normal distribution and equal variances) or the Mann-Whitney $U$-test was used if the distribution did not match the normal distribution. Statistical analysis was performed in the Statistica 12 program (Statsoft), the level of statistical significance was assumed to be $\alpha=0.05$.

\subsection{Ethics statement}

The research was approved prior to performing the study by the bioethics commission, approval no. 529/13, of Poznan University of Medical Sciences. All patients participating in the project received comprehensive information about the conducted research, as well as written consent to participate in the study was obtained each time.

\section{Results}

\subsection{Histomorphometry and the degree of rib mineralization}

The first stage of research included analysis of structural parameters of ribs and assessment of their mineralization (BMD). Based on the images recorded using microCT, basic parameters describing their geometry were calculated for each of the ribs (Table 1, Fig. 3). The obtained results indicate that floating ribs, compared to false ribs, are characterized by higher values of histomorphometric parameters such as Ct.Th, Ct.Vol, and Ct.Ar.

Table 1. Histomorphometric ribs parameters

\begin{tabular}{|l|c|c|c|}
\hline \multicolumn{1}{|c|}{ Ribs } & $\begin{array}{c}\text { cortical thickness } \\
{[\mathrm{mm}]}\end{array}$ & $\begin{array}{c}\text { cortical volume } \\
{[\%]}\end{array}$ & $\begin{array}{c}\text { BMD } \\
{\left[\mathrm{g} / \mathrm{cm}^{3}\right]}\end{array}$ \\
\hline & $\bar{x} \pm \mathrm{SD}$ & $\bar{x} \pm \mathrm{SD}$ & $\bar{x} \pm \mathrm{SD}$ \\
\hline False & $0.6 \pm 0.1$ & $52.7 \pm 9.4$ & $0.8 \pm 0.1$ \\
\hline Floating & $0.6 \pm 0.1$ & $56.5 \pm 10.6$ & $0.8 \pm 0.1$ \\
\hline
\end{tabular}

Due to the expanded cortical layer, the floating ribs have a smaller trabecular area than the false ribs (Fig. 3). Nevertheless, no statistically significant differences between the analyzed groups of ribs were observed for any of the histomorphometric parameters.

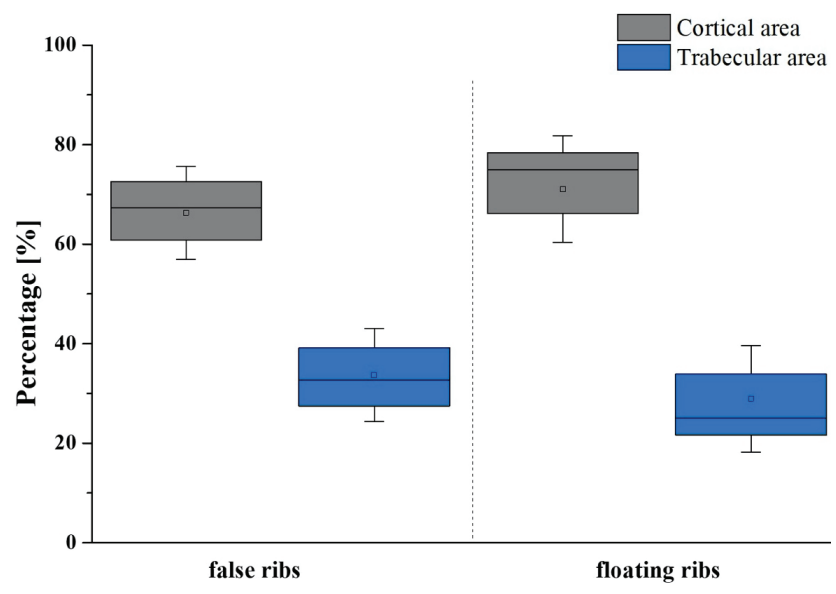

Fig. 3. Percentage share of cortical and trabecular area depending on the type of ribs, analyzing the values obtained for Ct.Th and Ct.Vol 


\subsection{Mechanical properties}

The next stage of the study was to assess the mechanical properties of the ribs. On the basis of the 3-point bending test, mechanical parameters illustrating the work of ribs under load were determined (Table 2). A statistically significantly higher Young's modulus $E$ and stiffness $K$ for false ribs compared to floating ribs were observed. In the case of $M_{g}$ bending moment, no statistically significant differences were found; however, the results obtained for false ribs in comparison with floating ribs are on the border of the accepted statistical significance.

Table 2. Mechanical parameters of false and floating ribs

\begin{tabular}{|l|c|c|c|}
\hline \multicolumn{1}{|c|}{ Ribs } & $\begin{array}{c}E \\
{[\mathrm{GPa}]}\end{array}$ & $\begin{array}{c}K \\
{\left[\mathrm{Nm}^{2}\right]}\end{array}$ & $\begin{array}{c}M_{g} \\
{[\mathrm{Nm}]}\end{array}$ \\
\hline & $\bar{x} \pm \mathrm{SD}$ & $\bar{x} \pm \mathrm{SD}$ & $\bar{x} \pm \mathrm{SD}$ \\
\hline False & $5.4 \pm 1.8$ & $220.2 \pm 93.3$ & $2.9 \pm 1.4$ \\
\hline Floating & $3.8^{*} \pm 1.6$ & $164.1^{*} \pm 52.8$ & $2.2 \pm 0.6$ \\
\hline
\end{tabular}

* Statistically significant differences in relations to false ribs $p<0.05$.

Analyzing the influence of the patient's age on the obtained mechanical properties, it can be noticed that in the case of Young's modulus $E$ in both age groups, there are statistically significant differences between the rib types. The false ribs have a higher modulus $E$ on average by $40 \%$ in comparison with floating ribs (Fig. 4).

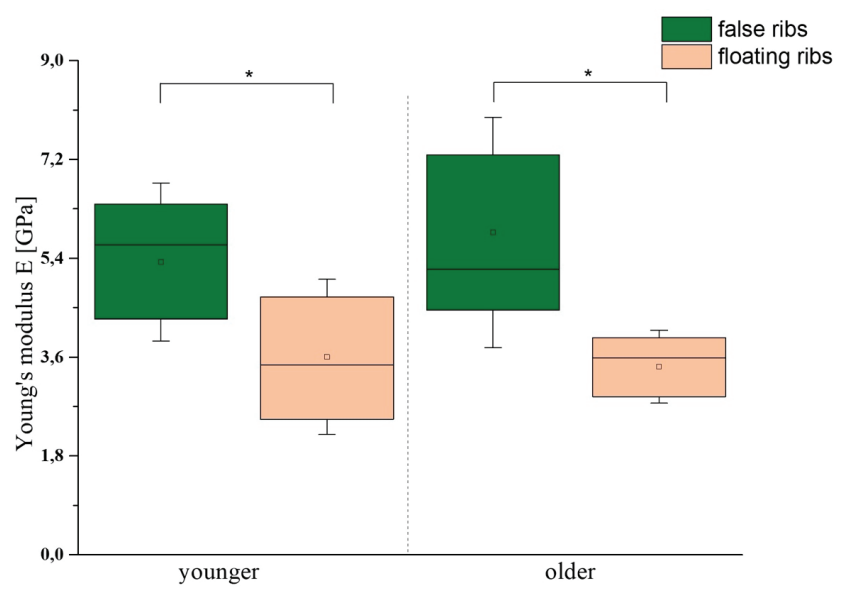

Fig. 4. Value of Young's modulus of ribs according to type of ribs and age of the patients; $* p<0.05$

In the case of stiffness, the statistically significant differences obtained indicate that the false ribs of young patients are stiffer not only compared to the floating ribs but also with respect to the same type of ribs of older patients (Fig. 5). Studies have shown that false ribs up in patients up to the age of 15 are twice as stiff as in those above the age of 15 .

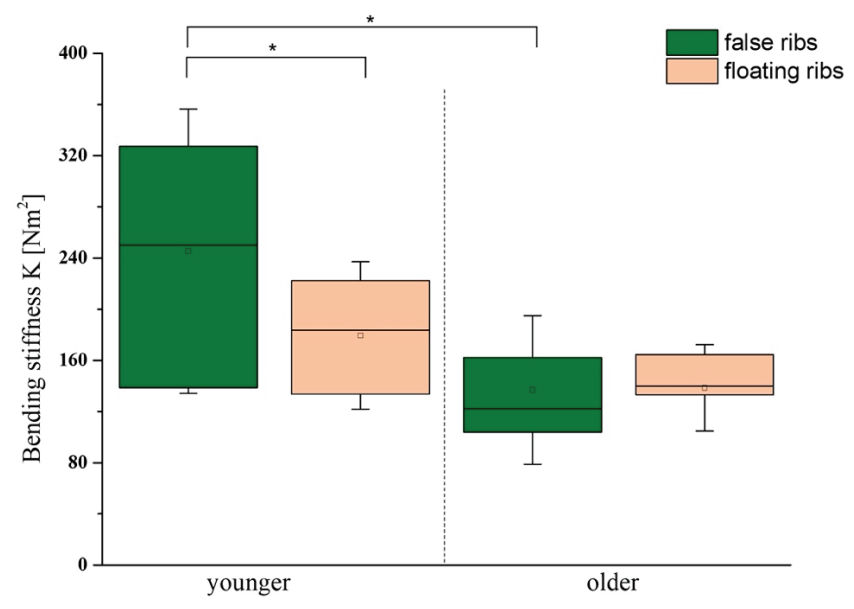

Fig. 5. Ribs stiffness value by type of ribs and patient's age; $* p<0.05$

No statistically significant differences in $M_{g}$ bending moment values were found for any of the analyzed groups (Fig. 6). The relationships in both age groups are of a similar nature.

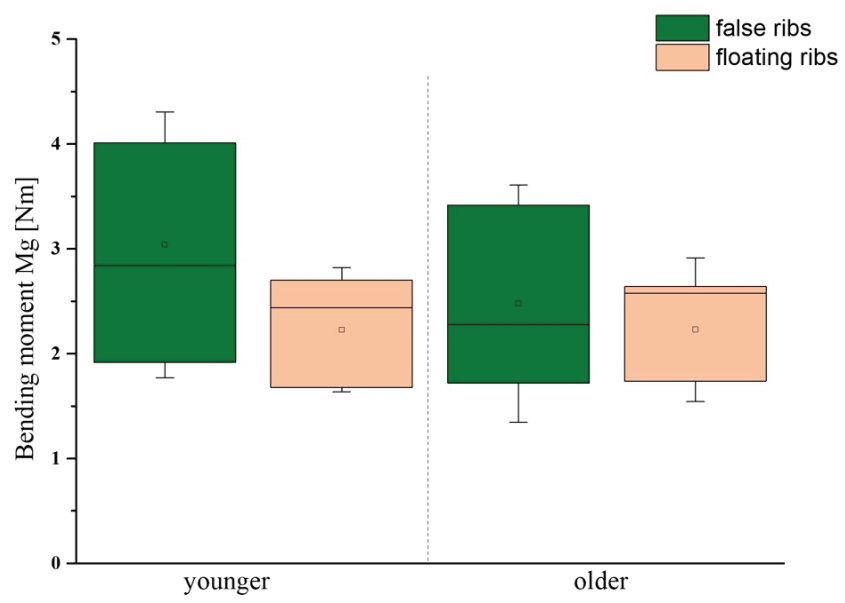

Fig. 6. $M_{g}$ value of ribs in accordance with the type of ribs and the patient's age; $* p<0.05$

\subsection{Correlations between parameters}

The last stage of research was the analysis of correlations between individual parameters (Table 3). From the clinical data, higher BMD values were correlated with more advanced donor's age, bigger height, and greater shoulder width. 
Table 3. Clinical parameters vs. BMD

\begin{tabular}{|l|l|l|}
\hline $\begin{array}{c}\text { Relationship } \\
\text { between the parameters }\end{array}$ & $r(p$ value $)$ & \multicolumn{1}{|c|}{ Interpretation } \\
\hline $\begin{array}{l}\text { Age vs. BMD } \\
{\left[\mathrm{g} / \mathrm{cm}^{3}\right]}\end{array}$ & $0.31(0.041)$ & $\begin{array}{l}\text { The greater the age, } \\
\text { the higher the BMD }\end{array}$ \\
\hline $\begin{array}{l}\text { Height }[\mathrm{cm}] \text { vs. BMD } \\
{\left[\mathrm{g} / \mathrm{cm}^{3}\right]}\end{array}$ & $0.47(0.001)$ & $\begin{array}{l}\text { The greater the height, } \\
\text { the higher the BMD }\end{array}$ \\
\hline $\begin{array}{l}\text { Arm span }[\mathrm{cm}] \text { vs. BMD } \\
{\left[\mathrm{g} / \mathrm{cm}^{3}\right]}\end{array}$ & $0.51(0.000)$ & $\begin{array}{l}\text { The greater the arm span, } \\
\text { the higher the BMD }\end{array}$ \\
\hline
\end{tabular}

In turn, the relationship between age and selected mechanical parameters of the ribs was not confirmed. The analysis also did not confirm the relationship between mechanical parameters and BMD. However, a relationship was demonstrated between stiffness and Young's modulus an increase of which was associated with lower cortical bone content (Table 4).

Table 4. Mechanical parameters vs. histomorphometry

\begin{tabular}{|c|c|c|}
\hline $\begin{array}{c}\text { Relationship } \\
\text { between the parameters }\end{array}$ & $r(p$ value $)$ & Interpretation \\
\hline$E[\mathrm{GPa}]$ and Ct.Ar [\%] & $-0.43(0.00)$ & $\begin{array}{l}\text { The greater the } E, \\
\text { the lower the cortical area }\end{array}$ \\
\hline$K\left[\mathrm{Nm}^{2}\right]$ and Ct.Ar [\%] & $-0.32(0.03)$ & $\begin{array}{l}\text { The greater the } K, \\
\text { the lower the cortical area }\end{array}$ \\
\hline
\end{tabular}

Table 5. Correlation between radiological vs. histomorphometrical and mechanical parameters

\begin{tabular}{|l|l|l|}
\hline \multicolumn{1}{|c|}{$\begin{array}{c}\text { Relationship } \\
\text { between the parameters }\end{array}$} & $r(p$ value $)$ & \multicolumn{1}{|c|}{ Interpretation } \\
\hline $\begin{array}{l}\text { Percent of correction } \\
\text { vs Ct.Ar [\%] }\end{array}$ & $0.37(0.012)$ & $\begin{array}{l}\text { The greater the percent } \\
\text { of correction, the higher } \\
\text { the cortical area }\end{array}$ \\
\hline $\begin{array}{l}\text { Percent of correction } \\
\text { vs Tb.Ar [\%] }\end{array}$ & $-0.37(0.012)$ & $\begin{array}{l}\text { The greater the percent } \\
\text { of correction, the lower } \\
\text { the trabecular area }\end{array}$ \\
\hline $\begin{array}{l}\text { Percent of correction } \\
\text { vs Ct.Vol [\%] }\end{array}$ & $0.39(0.008)$ & $\begin{array}{l}\text { The greater the percent } \\
\text { of correction, the higher } \\
\text { the cortical volume }\end{array}$ \\
\hline $\begin{array}{l}\text { Apical vertebrae } \\
\text { translation } \\
\text { [cm] vs Ct.Vol [\%] }\end{array}$ & $\begin{array}{l}\text { The greater the apical } \\
\text { vertebrae translation, } \\
\text { the lower the cortical } \\
\text { volume }\end{array}$ \\
\hline $\begin{array}{l}\text { Kyphosis angl } \\
\text { vs. } M_{g}[\mathrm{Nm}]\end{array}$ & $\begin{array}{l}\text { The greater the kyphosis } \\
\text { angle translation, } \\
\text { the higher the } M_{g}\end{array}$ \\
\hline $\begin{array}{l}\text { Kyphosis angle } \\
\text { vs. } K\left[\mathrm{Nm}{ }^{2}\right]\end{array}$ & $\begin{array}{l}\text { The greater the kyphosis } \\
\text { angle translation, } \\
\text { the higher the } K\end{array}$ \\
\hline
\end{tabular}

Among the radiological parameters, it was shown that higher values of the percent of correction were correlated with a higher value of Ct.Ar and Ct.Vol, and a lower value of $\operatorname{Tr}$.Ar (Table 5). In turn, higher values of the kyphosis angle were associated with an increase in such mechanical parameters as bending moment and stiffness. The last parameter discussed was the value of the apical vertebrae translation an increase of which was associated with a smaller Ct.Vol.

\section{Discussion}

\subsection{Quality of the analyzed bone tissue}

Material assessed in the form of human ribs collected in vivo, taking all ethical standards into account, is rarely found in the world literature in which the research is based mainly on bone tissue collected from deceased people, often burdened with a number of chronic diseases which have a significant influence on the mechanical properties [1], [6], [12], [20], [21], [25].

The fact that bone material is selected for testing from patients with scoliosis prompts a broader assessment of this disorder in terms of its effect on the mechanical strength of the ribs. Scoliosis, according to the literature data, is a disease entity often associated with lower body weight and, consequently, a lower BMI [3].

Some authors state that scoliosis is associated with reduced bone mass, and the cause of these disorders may be poor nutrition or decreased physical activity resulting from the illness [13].

In the opinion of authors such as Cheung et al. [3], based on a study of over 170 people, osteopenia among patients with scoliosis is more common than in the age-appropriate general population.

Contrary to these reports, Wang et al. [24] do not confirm such a significantly increased percentage of patients with osteopenia in the group of people with scoliosis however, assessing that it may affect up to $30 \%$ of this population. Despite these reports, densitometry is not a routine procedure in preparation for surgery for idiopathic scoliosis.

In our material, the BMD results of the analyzed rib fragments are similar to those reported in the paper by Mailhot et al. [14]. The BMD value of the rib fragments obtained during the procedure of collecting thoracic organs for transplantation was $0.926\left[\mathrm{~g} / \mathrm{cm}^{3}\right]$. These are BMD values comparable to our work, in which the average BMD value was $0.8860\left[\mathrm{~g} / \mathrm{cm}^{3}\right]$ (Table 1).

\subsection{Mechanical and histomorphometric tests of ribs}

In the work by Granik and Stein [6], 3-point bending analysis was performed on ribs VI and VII. The study 
material was obtained during the section from 10 people, whose ribs did not show demineralization features in an X-ray examination of the chest, without reference to the cause of death [6]. In such measurements, the average Young's modulus values were more than twice as high, i.e., $11.5 \mathrm{GPa}$, compared to the results in our work, in which the average Young's modulus value was $4.81 \mathrm{GPa}$. Among the possible causes of such significant discrepancies, not only the previously discussed aspects related to the proper selection of bone material can be mentioned. The discussed work also uses a different loading speed.

In addition, the assessment of the thickness of the cortical bone layer at the fracture site was based on macroscopic methods associated with a much greater margin of error compared to modern measurements made using a microtomograph [6]. In the study of Stein and Granik [20], ribs collected from as many as 79 male donors were examined. In the assessment of mechanical properties, the 3-point bending method was used, but taking into account three different loading speeds. Samples from donors aged 27 to 83 years were tested. The authors did not observe the relationship between the harvesting site of the fragment of the rib, geometric parameters, and bending strength.

Contrary to Stein and Granik [20], in our work, we noticed a relationship between the percentage of the cortical bone and the value of Young's modulus and stiffness the increase of which was associated with a decrease in the percentage of cortical bone of the examined ribs (Table 4). A relationship between the age and the mechanical properties was also observed, in which ribs taken from persons from the younger age group (up to 15 years old) were characterized by a greater rigidity.

In turn, Stein and Granik [20] described the correlation between age and maximum destructive force, noting its decrease as the age of donors increased. The values of Young's modulus reported by Granik and Stein [6] are most similar to those described in the study by Stitzel et al. [21], in which the cortical bone fragments of ribs from 4 people aged 61 to 71 were subjected to the dynamic assessment of the 3-point bending test. At the same time, bone mineral density assessment showed osteoporosis in three donors, while osteopenia was diagnosed in one donor. Stitzel et al. [21] obtained average Young's modulus values in the range from $7.51 \mathrm{GPa}$ for rib fragments taken from the anterior chest up to $11.9 \mathrm{GPa}$ for cortical rib fragments taken from the lateral chest. The rigidity of the examined rib fragments depended on the anatomical location of the sampling site of the examined rib [9], [21]. Those reports are consistent with the results of our research in which differences between the assessed groups of ribs were also observed, noting higher values of Young's modulus and stiffness within the group of false ribs in relation to floating ribs (Table 2). During physical activity, the highest mechanical values are concentrated in the lateral thoracic region. This has important clinical consequences, as the V-IX ribs in the posterior lateral region are most commonly affected by fatigue fractures [10]. From an anatomical point of view, this is the location of the interpenetrating serratus anterior and external oblique muscle attachments, the simultaneous contraction of which causes significant tension within true and false ribs, sometimes resulting in a fracture.

On the other hand, fatigue fractures of floating ribs to which the external oblique muscle attaches do not constitute a significant clinical problem from an epidemiological perspective. It is associated with a lower concentration of stress during intense physical activity, which translates into fewer fractures [15].

Returning to the issue of quantitative analysis of bone tissue, the work of Stitzel et al. [21] confirms the correlation between higher mineral density of the analyzed bone tissue and stiffness of the examined rib fragments, and higher values of Young's modulus. Higher values of stiffness and Young's modulus were associated with a greater degree of bone mineralization.

This fact was not confirmed in our studies in which no statistically significant correlation was obtained between the mineral density of the sample and its mechanical properties. However, correlations between age, height, and higher BMD of the analyzed rib fragments were confirmed (Table 3 ).

In turn, paradoxically, it is the younger age group (up to 15 years) that was characterized by statistically significantly higher stiffness (Fig. 5), which is reflected in different structural parameters in which the increase in stiffness was connected with the smaller cortical bone surface. In this context, the reports of Keaveny et al. [11] which indicate the limited usefulness of the quantitative parameter which is BMD in the context of the risk of a fracture, because it can be different even at similar bone mineral density values, are important. In addition to inorganic components, the bone tissue consists of an organic substance in the form of collagen fibers, non-collagen proteins, and proteoglycans, of which proportions determine the final strength of bone tissue, and thus the clinical risk of fracture [11].

Among the works in which human ribs were analyzed using the force directed from the inside to the outside of the chest, the study of Pezowicz and 
Glowacki [17] needs to be mentioned in which material from juvenile donors aged 10 to 22 was evaluated. The provided Young's modulus values were on average $4.71 \mathrm{Gpa}$, which is a result similar to those obtained in our work as well as those given by Agnew et al. [1]. The authors demonstrated the existence of a relationship between age and elasticity module, noting its higher values for ribs obtained from donors from the older age group, in this case 16-22 years of age [17]. The value of stiffness and bending moment were similar to the results reported by Kemper et al. [12]. In turn, the average value of the bending moment given by Pezowicz and Głowacki [17] was $2.73 \mathrm{Nm}$, which is a result similar to the values published in the research by Kemper et al. [12], which provides the values of the moment bending of an average of $5.5 \mathrm{Nm}$. Slightly different results regarding the mechanical properties of human ribs are presented in the paper by Agnew et al. [1]. Extensive analysis was performed on 44 anterolateral segments collected from twelve donors aged only from 5 months to 9 years, i.e., during periods of rapid developmental changes [1]. In assessing the mechanical properties carried out by the 3-point bending method with a loading speed identical to that used in the work of Yoganandan et al. [25], the average Young's modulus value of $4.86 \mathrm{GPa}$ was obtained, while the average bending moment value was $1.02 \mathrm{Nm}$. The average stiffness value was $29.81 \mathrm{~N} / \mathrm{mm}$ [1]. The authors showed a statistically significant relationship between parameters such as age, height, bending moment, and Young's modulus. The relationship between maximum destructive force and age was also confirmed. As a result of the analysis, a statistically significant relationship between the bending moment and the cortical bone surface was found. An identical correlation was obtained in the case of stiffness and Young's modulus, the increase in the value of these parameters was associated with a larger cortical bone surface [1].

This is not confirmed by the presented studies in which higher values of Young's modulus and stiffness were obtained for ribs with a smaller cortical bone surface (Table 4).

The effect of age on mechanical parameters was only significant in the case of stiffness, after taking the division into age groups into account (Fig. 5). On the other hand, in the studies of Schafman et al. [18], significant variability in the mechanical parameters of the ribs was found without a clear influence of the age and sex of the sample donors. Similar conclusions were formulated in the paper by Agnew et al. [1], in which the age also did not significantly affect the me- chanical properties of the ribs. There are few studies in the literature regarding thoracic mechanics, including ribs, in patients with scoliosis [16], [23].

So far, the radiological parameters characterizing scoliosis in combination with the 3-point bending test, and the evaluation of the morphometry of the assessed rib fragments have not been simultaneously analyzed.

Paradoxically, parameters describing better scoliosis correction, such as the value of pre-operative percentage of correction in the so-called corrective tilt were associated with a larger volume and area of the cortical bone. In turn, radiological parameters, such as increased apical vertebrae translation, indicating greater rigidity of the main curvature arc, were associated with the smaller cortical bone area. In the 3-point bending test, the maximum destructive force, stiffness, and bending moment were correlated with higher values of the kyphosis angle, a parameter which also indicates clinically greater stiffness of the main scoliosis arc (Table 5).

\section{Conclusions}

Mechanical and histomorphometric properties of bone tissue in patients with scoliosis are not explicitly associated with the radiological parameters characterizing scoliosis, but are associated with the age of patients and the anatomical location of the ribs.

\section{Acknowledgements}

This research did not receive any specific grant from funding agencies in the public, commercial, or not-for-profit sectors.

\section{References}

[1] Agnew A.M., Moorhouse K., KANG Y.S. et al., The response of pediatric ribs to quasi-static loading: mechanical properties and microstructure, Ann. Biomed. Eng., 2013, 41 (12), 2501-2514.

[2] Cheng J.C.Y., Guo X., Sher A.H.L., Persistent osteopenia in adolescent idiopathic scoliosis, Spine, 1999, 24 (12), $1218-1222$.

[3] Cheung C.S., Lee W.T., Tse Y.K. et al., Generalized osteopenia in adolescent idiopathic scoliosis - association with abnormal pubertal growth, bone turnover, and calcium intake?, Spine, 2006, 31 (3), 330-338.

[4] D'ANDREa P.L., Betz R.R., Lenke G.L. et al., Do radiographic parameters correlate with clinical outcomes in adolescent idiopathic scoliosis?, Spine, 2000, 25 (14), 1795-1802. 
[5] DobrzyŃski M., Pezowicz C., Tomanik M. et al., Modulating effect of selected pharmaceuticals on bone in female rats exposed to 2, 3, 7, 8-tetrachlorodibenzo-p-dioxin (TCDD), RSC Advances, 2018, 8 (48), 27537-27545.

[6] GRANIK G., STEIN I.D., Human ribs: static testing as a promising medical application, J. Biomech., 1973, 6 (3), 237-240.

[7] Gzik-Zroska B., Wolanski W., Kawlewska E. et al., Computer-aided correction of pectus carinatum, Proceedings of VIPIMAGE, 2013, 341-344.

[8] Hamer A.J., Strachan J.R., Black M.M. et al., Biochemical properties of cortical allograft bone using a new method of bone strength measurement. A comparison of fresh, fresh-frozen and irradiated bone, J. Bone Joint Surg. Br., 1996, 78 (3), 363-368.

[9] Jastrzebski D., Perz R., Rib kinematics analysis in oblique and lateral impact tests, Acta Bioeng. Biomech., 2020, 22 (1), 135-141.

[10] KARLSON K.A., Rib stress fractures in elite rowers: a case series and proposed mechanism, Am. J. Sports Med., 1998, 26 (4), 516-519.

[11] Keaveny T.M., Kopperdahl D.L., Melton L.J. 3rd et al., Age dependence of femoral strength in white women and men, J. Bone Miner. Res., 2010, 25 (5), 994-1001.

[12] Kemper A.R., McNally C., Pullins C.A. et al., The biomechanics of human ribs: material and structural properties from dynamic tension and bending tests, Stapp Car Crash J., 2007, 51, 235-273.

[13] LI X.F, LI H., LIU Z.D., DAI L.Y., Low bone mineral status in adolescent idiopathic scoliosis, Eur. Spine J., 2008, 17 (11), 1431-1440.

[14] Mailhot G., Dion N., Farlay D. et al., Impaired rib bone mass and quality in end-stage cystic fibrosis patients, Bone, 2017, 98, 9-17.

[15] Miles J.W., BARRetT G.R., Rib fractures in athletes, Sports Medicine, 1991, 12 (1), 66-69.
[16] Oda I., Abumi K., Cunningham BW. et al., An in vitro human cadaveric study investigating the biomechanical properties of the thoracic spine, Spine, 2002, 27 (3), 64-70.

[17] Pezowicz C., Glowacki M., The mechanical properties of human ribs in young adult, Acta Bioeng. Biomech., 2012, 14, $53-56$.

[18] Schafman M.A., Kang Y.S., Moorhouse K. et al., Age and sex alone are insufficient to predict human rib structural response to dynamic A-P loading, J. Biomech., 2016, 49 (14), 3516-3522.

[19] Skoczylas K., Analysis of ribs failure force in three-point bending test, Dissertation Wroclaw University of Science and Technology, 2012.

[20] SteIn I.D., GRANiK G., Rib Structure and Bending Strength: An Autopsy Study, Calcif Tissue Res., 1976, 20 (1), 61-73.

[21] Stitzel J.D., Cormier J.M., Barretta J.T. et al., Defining regional variation in the material properties of human rib cortical bone and its effect on fracture prediction, Stapp Car Crash J., 2003, 47, 243-265.

[22] SuK S.I., KIm J.H., KIm S.S. et al., Thoracoplasty in thoracic adolescent idiopathic scoliosis, Spine, 2008, 33 (10), 1061-1067.

[23] Upadhyay S.S., Mullaji A.B., LuK K.D., LeOng J.C., Relation of spinal and thoracic cage deformities and their flexibilities with altered pulmonary functions in adolescent idiopathic scoliosis, Spine, 1995, 20 (22), 2415-2420.

[24] Wang Z.W, LeE W.Y, Lam T.P. et al., Defining the bone morphometry, micro-architecture and volumetric density profile in osteopenic vs non-osteopenic adolescent idiopathic scoliosis, Eur. Spine J., 2017, 26 (6), 1586-1594.

[25] Yoganandan N., Pintar F.A., Biomechanics of Human Thoracic Ribs, J. Biomech. Eng., 1998, 120, 100-104. 